\title{
Caregivers' resilience is independent from the clinical symptoms of dementia
}

\author{
A resiliência dos cuidadores independe dos sintomas clínicos da demência \\ Rachel Dias' ${ }^{1}$ José Pedro Simões-Netoㄹ, Raquel Luiza Santos' ${ }^{1}$, Maria Fernanda Barroso de Sousa ${ }^{1}$, Maria \\ Alice Tourinho Baptista1 , Isabel Barbeito Lacerda', Nathalia Ramos Santos Kimura', Marcia Cristina \\ Nascimento Dourado ${ }^{1}$
}

\begin{abstract}
Resilience is the capacity for successful adaptation when faced with the stress of adversity. We aimed to investigate the relationship between caregivers' resilience and the sociodemographic and clinical factors of people with dementia. Cross-sectional assessment of 58 people with dementia and their caregiver dyads showed that most caregivers were female adult children. The caregivers reported moderate to higher levels of resilience, lower levels of anxiety and depressive symptoms and moderate levels of burden. Resilience was not related to the caregiver's gender ( $p=0.883$ ), nor clinical $(p=0.807)$ or emotional problems $(p=0.420)$. The regression showed that resilience was related to the caregiver's quality of life $(p<0.01)$ and inversely associated with their depressive symptoms $(p<0.01)$. There was no relationship between caregivers' resilience and the sociodemographic and clinical characteristics of people with dementia. We can assume that resilience is an individual characteristic. Support groups should also focus on the factors that may increase resilience among caregivers.
\end{abstract}

Keywords: resilience, psychological; caregivers; dementia; depression; quality of life.

\section{RESUMO}

Resiliência é a capacidade de adaptação bem-sucedida, quando confrontado com o estresse da adversidade. Nosso objetivo foi investigar a relação entre a resiliência dos cuidadores e fatores sociodemográficos e clínicos de pessoas com demência. A avaliação transversal de 58 pessoas com demência e suas duplas de cuidadores, mostrou que a maioria dos cuidadores eram do sexo feminino e filhas adultas. Os cuidadores relataram níveis moderados a altos de resiliência, níveis mais baixos de ansiedade e sintomas depressivos e níveis moderados de sobrecarga. Resiliência não estava relacionada ao gênero $(p=0.883)$ e problemas clínicos $(p=0.807)$ e emocionais $(p=0.420)$ dos cuidadores. A regressão mostrou que a resiliência foi relacionada à qualidade de vida $(p<0,01)$ dos cuidadores e inversamente associada com os sintomas depressivos ( $p<0,01$ ). Não havia uma relação significativa entre a resiliência dos cuidadores e as características sociodemográficos e clínicas das pessoas com demência. Podemos supor que a resiliência é uma característica individual. Os grupos de apoio devem enfatizar os fatores que podem aumentar a resiliência entre os cuidadores.

Palavras-chave: resiliência psicológica; cuidadores; demência; depressão; qualidade de vida.

Dementia leads to a progressive and irreversible cognitive and functional impairment ${ }^{1}$. People with dementia require continuous care, which, in most cases, is carried out by their own family members ${ }^{1}$. Caregivers can be particularly burdened by the constant symptoms of the disease ${ }^{2}$. Some studies have shown that cognitive impairment, dependence in activities of daily living and behavioral disorders of people with dementia are probably the most important predictors of burden and depression in caregivers ${ }^{3,4,5,6,7}$. Consequently, high levels of anxiety, depression, emotional burden and low levels of subjective well-being, self-efficacy and quality of life have been observed in caregivers ${ }^{2,3,8}$.

Caregivers face many difficulties; however they may also experience positive emotional responses ${ }^{9}$. Resilience, satisfaction with caregiving, coping, social support and a strong sense of spirituality have been posited as protective factors that mediate negative health outcomes ${ }^{6}$. Other mediating mechanisms are coping strategies and a sense of coherence ${ }^{9}$. Coping strategies are a dynamic set of cognitive and behavioral efforts to cope with internal and external demands perceived

`Universidade do Rio de Janeiro, Instituto de Psiquiatria, Centro para Doenças de Alzheimer e outras Desordens Mentais na Velhice, Rio de Janeiro RJ, Brasil; Universidade Federal de Santa Catarina, Departamento de Sociologia e Ciência Política, Florianópolis SC, Brasil.

Correspondence: Rachel Dias Lopes da Rosa; Rua Carolina Alves, 07; 24322-310 Niterói RJ, Brasil; E-mail: diasrachel@gmail.com Conflict of interest: There is no conflict of interest to declare.

Support: This study was supported by CNPq - Conselho Nacional de Desenvolvimento Científico e Tecnológico - Brasil. Rachel Dias is a master's fellow from CAPES - Coordenação de Aperfeiçoamento de Pessoal de Nivel Superior.

Received 03 June 2016; Received in final form 21 July 2016; Accepted 14 September 2016. 
as burdens when compared with personal resources ${ }^{10}$. In contrast, the sense of coherence depends on the ability to realize that the situation is understandable or predictable and to perceive one's ability to cope in a difficult situation and to find meaning in everyday events or problems faced ${ }^{11}$.

Resilience has been defined as one's capacity for successful adaptation when faced with the stress of adversity ${ }^{12}$. One of the mechanisms by which resilience facilitates adaptation has been described as the ability to identify what is stressful, realistically appraise one's capacity for action, and solve problems effectively ${ }^{13}$. The construct can be considered as a dynamic process involving the interaction between internal or external risks and protective factors that act to modify the effects of an adverse life event on the individual ${ }^{14}$. Resilience is not invulnerability to stress, but, rather, the ability to recover from negative events ${ }^{14}$. This concept corresponds to a transactional process, mediated by the interaction between the individual and the environment.

Resilience is also considered as a personality characteristic $^{15}$. Some personality factors, such as a sense of competence, may moderate the relationship between caring and burden and, consequently, are associated with positive feelings in caregiving ${ }^{8,15}$. In general, greater control over life helps adaptation and improves understanding of the situation, acceptance of changes and the confidence of caregivers in their own strength and inn the affective bonds shared with care recipients ${ }^{2}$. Also, optimistic people make a subjective estimate of the probability of achieving goals or desired results based on other factors, such as self-efficacy (belief in their own capacity for starting actions and dealing with life) and internal locus of control or contingency (how individuals expect life events or results to be motivated by their actions) ${ }^{8}$.

However, in dementia research, it is not clear whether caregivers' resilience is an individual characteristic or related to the clinical variables of people with dementia. In this context, we aim to investigate the relationship between resilience and sociodemographic and clinical factors of people with dementia. Our hypothesis is that caregivers' resilience is a personality trait, independent from the clinical symptoms of the person with dementia.

\section{METHODS}

\section{Participants}

In a cross-sectional design, we included 58 people with dementia and caregiver dyads consecutively selected, according to their physicians' referral. Participants attended a dementia outpatient clinic in Rio de Janeiro for routine follow-up appointments

The people with dementia were diagnosed with possible or probable Alzheimer's disease, vascular dementia and mixed dementia according to the Diagnostic and Statistical Manual of Mental Disorders, Fourth Edition (DSM-IV-TR) ${ }^{16}$.
People with mild to moderate dementia according to the Clinical Dementia Rating ${ }^{17}$ and scores ranging from 13 to 26 in the Mini-Mental State Examination (MMSE) ${ }^{18}$ were included in the study. We excluded patients with more severe dementia due to difficulties in assessment. To ensure the findings were applicable to dementia rather than to other clinical problems, people with dementia with uncontrolled clinical problems, psychiatric disorders, aphasia, head trauma, alcohol abuse and epilepsy, as defined by the DSM-IV-TR ${ }^{16}$ criteria, were excluded from the study. The primary caregiver was defined as the main person responsible for the care of the person with dementia. We included only informal caregivers. We excluded caregivers with a reported history of psychiatric or cognitive disorders. The caregivers provided detailed information about their care recipients. All caregivers had been previously informed of the diagnosis. The person with dementia completed assessments for quality of life (QoL), cognition and awareness of their disease. Caregivers had QoL, resilience, depression, hopelessness, anxiety and burden of care assessed. They also provided information about the person with dementia, including demographics, mood, neuropsychiatric symptoms, dementia severity and the ability to perform activities of daily living.

This study was approved by the Ethics Committee of the Institute of Psychiatry of the Federal University of Rio de Janeiro (IPUB/ UFRJ) and all people with dementia and caregivers signed informed consent forms prior to the first interview.

\section{Measurements}

Sociodemographic data for patients and caregivers were gathered using a structured questionnaire. We used the Brazilian adaptation of all clinical instruments.

\section{Caregivers' Measurements}

\section{Resilience}

The Resilience Scale by Wagnild and Young, is the most-used in dementia research ${ }^{12}$. It has 25 items that measure levels of positive adaption in the face of adverse life events. The scale considers resilience construct, serenity, perseverance, self-confidence, sense of life and self-sufficiency ${ }^{19}$. The scale scores range from 25 to 175 , with higher values indicating greater resilience.

\section{Hopelessness}

The Beck Hopelessness Scale ${ }^{20}$ is a self-report instrument and has 20 items that investigate negative expectations of the future. The scale scores range from zero to 20 , with higher values indicating greater hopelessness.

\section{Quality of Life}

The Quality of Life in Alzheimer's Disease Scale (QoL-AD) caregivers' version (CQoL) ${ }^{21}$ comprises 13 items. The total score ranges from 13 to 52 . Higher scores indicate a higher level of QoL. 


\section{Burden}

The Zarit Burden Interview ${ }^{22}$, comprises 22 items that measure the impact of the person with dementia's illness on the caregiver's life. Scores range from zero to 88 , with higher scores indicating greater level of burden.

\section{Depression}

The Beck Depression Inventory ${ }^{20}$, is a self-report scale. The scale scores range from zero to 63, with higher scores indicating an increased level of depression.

\section{Anxiety}

The Beck Anxiety Inventory ${ }^{20}$, has 21 items. The scale scores range from zero to 68 , with higher scores indicating a higher level of anxiety.

\section{Cognition}

The MMSE ${ }^{18}$, is an instrument that comprises tests of orientation, registration, short-term memory, language use, comprehension and basic motor skills. The total score ranges from zero to 30 .

\section{People with Dementia Measurements}

\section{Severity of Dementia}

The full protocol of the Clinical Dementia Rating ${ }^{17}$, in which the possible stages of severity include 0 (no dementia), 0.5 (questionable dementia), 1 (mild dementia), 2 (moderate dementia) and 3 (severe dementia).

\section{Quality of Life}

The QoL- $\mathrm{AD}^{21}$ is the same scale used to assess the caregivers' QoL, but we used both the self-report of the person with dementia's (PQoL) and the caregiver's perspective about the patient $(\mathrm{C}-\mathrm{PQOL})^{21}$. We analyzed the total scores separately. The total score ranges from 13 to 52 .

\section{Cognition}

The MMSE ${ }^{18}$ was also used to assess the caregivers' cognition.

\section{Functionality}

The Pfeffer Functional Activities Questionnaire ${ }^{23}$ has ratings for each item ranging from normal (0) to dependent (3), with a total of 30 points. Higher scores indicate worse functional status.

\section{Depression}

The Cornell Scale for Depression in Dementia ${ }^{24}$ assesses mood symptoms, physical signs, circadian functions and behavioral symptoms related to depression among people with dementia. Scores above 13 indicate the presence of depression.

\section{Neuropsychiatric Symptoms}

The 12-item Neuropsychiatric Inventory ${ }^{25}$ was applied. The total score ranges from zero to 144 . Higher scores indicate greater levels of neuropsychiatric symptoms.

\section{Awareness of the Disease}

We applied the Assessment Scale of Psychosocial Impact of the Diagnosis of Dementia ${ }^{26}$, a 30-question scale with scores based on the discrepancies between the reports of the person with dementia and the caregivers about awareness of cognitive deficits, social relationships, family relationships, instrumental and basic activities of daily living and affective relationships. The ratings range from preserved (0-4), mildly impaired (5-11), moderately impaired (12-17) to absent (over 18) awareness of disease.

\section{Statistical analysis}

All variables were inspected for normality before analysis. The parametric variables were described by their mean and standard deviations. The sociodemographic and clinical characteristics of the caregiver-person with dementia dyads were analyzed with descriptive statistics. We used the independent $\mathrm{t}$-test, the chi-square test and the ANOVA test to assess the relationship between resilience and sociodemographic and clinical variables.

Matrices of Pearson's correlations were created to investigate correlations between resilience and age, gender, educational level, duration of the disease, awareness of disease, cognitive function, functional activities, depressive symptoms, anxiety, hopelessness and caregiver burden. To control for family-wise error rates, only results with $p \leq 0.01$ were considered significant.

Based on the significant correlations, multivariate linear regressions were performed to determine the factors related to the caregivers' resilience. The best models were selected on the basis of a trade-off between the highest explained variance $\left(R^{2}\right)$ and highest cross-validity (adjusted $R^{2}$ ).

All statistical analyses were performed with SPSS software for Windows version 22.0. For all analyses, with the exception of the correlations, the $\alpha$-level was set at $p \leq 0.05$.

\section{RESULTS}

\section{Sociodemographic Characteristics}

\section{Caregivers}

Most caregivers were female (79.3\%) and married (77.6\%), with a mean age of $62.5 \pm 13.4$ years. Mostly, caregivers were adult children of the person with dementia (51.7\%). A large number of caregivers $(43.1 \%$ ) reported full time daily care of the person with dementia, $69 \%$ received assistance with the care, $51.7 \%$ presented with clinical problems (spinal problems, osteoporosis and hypertension), and 55.2\% reported emotional problems.

\section{People with Dementia}

The majority of the people with dementia were female (56.9\%) with a mean age of $78.2 \pm 6.66$ years. The mean age 
of onset of dementia was $73.1 \pm 7.59$ years. The people with dementia had an average of $5.2 \pm 3.45$ years since disclosure of their diagnosis.

The sociodemographic characteristics of the caregivers and people with dementia are presented in Table 1.

\section{Clinical Characteristics of Caregiver-Person with Dementia Dyads}

Our sample showed moderate to high levels of resilience, with a mean score of $137.66 \pm 15.54$. The caregivers were not cognitively impaired (28.9 \pm 1.39$)$, showed moderate levels of burden $(29.1 \pm 15.68)$ and lower levels of anxiety $(8.6 \pm 7.89)$ and depressive symptoms $(7.8 \pm 7)$. The majority of the

Table 1. Sociodemographic characteristics of caregivers and people with dementia.

\begin{tabular}{|c|c|}
\hline Caregivers & Total $(n=58)$ \\
\hline Age, mean (SD) & $62.5(13.44)$ \\
\hline Schooling, mean (SD) & $11.9(3.02)$ \\
\hline Females (\%) & 46 (79.3) \\
\hline \multicolumn{2}{|l|}{ Marital status (\%) } \\
\hline Singles & $6(10.3)$ \\
\hline Married & $45(77.6)$ \\
\hline Widowers & $3(5.2)$ \\
\hline Divorced & $4(6.9)$ \\
\hline \multicolumn{2}{|l|}{ Kinship (\%) } \\
\hline Children & $30(51.7)$ \\
\hline Spouses & $26(44.8)$ \\
\hline Others & $2(3.4)$ \\
\hline \multicolumn{2}{|l|}{ Time of care (daily) (\%) } \\
\hline Full & $25(43.1)$ \\
\hline Less than 6 hours (\%) & $11(19)$ \\
\hline 6 hours & $4(6.9)$ \\
\hline 8 hours & $7(12.1)$ \\
\hline 12 hours & $5(8.6)$ \\
\hline Occasionally & $6(10.3)$ \\
\hline $\begin{array}{l}\text { Duration of caregiver function (months), } \\
\text { mean (SD) }\end{array}$ & $53.9(49.32)$ \\
\hline People with dementia & Total $(n=58)$ \\
\hline Age, mean (SD) & $78.2(6.66)$ \\
\hline Schooling, mean (SD) & $7.5(3.82)$ \\
\hline Females (\%) & $33(56.9)$ \\
\hline \multicolumn{2}{|l|}{ Marital status (\%) } \\
\hline Singles & $3(5.2)$ \\
\hline Married & $32(55.2)$ \\
\hline Widowers & $22(37.9)$ \\
\hline Divorced & $1(1.7)$ \\
\hline Age of onset, mean (SD) & $73.1(7.59)$ \\
\hline Years of disease, mean (SD) & $5.2(3.45)$ \\
\hline
\end{tabular}

people with dementia presented as having mild dementia with a score on the Clinical Dementia Rating of 1 (74.1\%) and a mean MMSE score of $19.7 \pm 4.39$. The clinical characteristics of the caregiver-person with dementia dyads are summarized in Table 2.

\section{Factors Related to Resilience of Caregivers}

We did not find a relationship between resilience and caregivers' gender $(p=0.883)$, nor clinical $(p=0.807)$ and emotional problems $(p=0.420)$. There was no significant relationship between caregivers' resilience and the sociodemographic and clinical characteristics of the person with dementia.

\section{Univariate analysis}

We found a correlation between resilience and caregivers' depressive symptoms $(r=-0.539 ; \mathrm{p}<0.01)$, anxiety $(\mathrm{r}=-0.334$; $\mathrm{p}<0.01)$ and CQoL $(\mathrm{r}=0.514 ; \mathrm{p}<0.01)$. Caregivers' resilience is inversely related to their own depressive symptoms and anxiety. In addition, caregivers with higher scores on resilience also showed higher scores in CQoL. The significant and non-significant correlations are shown in Table 3.

Table 2. Clinical characteristics of caregivers and people with dementia.

\begin{tabular}{|cc|}
\hline Caregivers & Total $(n=58)$ \\
\hline RS & Mean (SD) \\
\hline CQoL & $37.6(15.54)$ \\
\hline MMSE & $28.8(5.49)$ \\
\hline ZBI & $29.1(15.68)$ \\
\hline BDI & $7.8(7)$ \\
\hline BAl & $8.6(7.89)$ \\
\hline BHS & $3.8(1.39)$ \\
\hline People with dementia & Total $(n=58)$ \\
\hline ASPIDD & Mean (SD) \\
\hline PQoL & $9.2(4.24)$ \\
\hline C-PQoL & $34.6(5.21)$ \\
\hline MMSE & $29.8(5.34)$ \\
\hline CSDD & $19.7(4.39)$ \\
\hline FAQ & $8.7(6.07)$ \\
\hline NPI & $15.7(7.98)$ \\
\hline CDR 1 \% & $15.9(16.35)$ \\
\hline
\end{tabular}

SD: standard deviation; RS: resilience scale; CQoL: quality of life in Alzheimer's disease scale (caregivers' reports on their own quality of life); MMSE: mini-mental state examination; ZBI: Zarit Burden interview; BDI: beck depression inventory; BAl: beck anxiety inventory; BHS: beck hopelessness scale;ASPIDD: scale of psychosocial impact of the diagnosis of dementia; PQoL: quality of life in Alzheimer's disease scale (patients' reports on their own quality of life); C-PQoL: quality of life in Alzheimer's disease scale (caregivers' reports on patients' quality of life; CSDD: Cornell scale for depression in dementia; FAQ: Pfeffer functional activities questionnaire; NPI: neuropsychiatric inventory; CDR: clinical dementia rating. 


\section{Multivariate analysis}

The linear regression model examined the relationship of the resilience and the variables that were significantly correlated (depressive symptoms, anxiety and CQoL). The linear regression indicated that resilience was significantly related to the depressive symptoms $(\mathrm{p}<0.01)$ and the QoL $(\mathrm{p}<0.01)$ experienced by the caregivers. The final model with factors associated with resilience explained $37.8 \%$ of the observed variance $(p<0.05)$. The adjusted $R^{2}$ values and the standardized regression weights are presented in Table 4.

\section{DISCUSSION}

The current study investigated the relationship between caregivers' resilience and the sociodemographic and clinical factors of people with dementia. We found moderate to high

Table 3. Correlation between resilience and study variables.

\begin{tabular}{|lcc|}
\hline Variable & $\mathrm{R}$ & $\mathrm{P}$ \\
\hline Caregivers & & \\
\hline Schooling & -0.119 & 0.374 \\
\hline Time of care & 0.122 & 0.360 \\
\hline CQoL & 0.514 & $0.000^{\star *}$ \\
\hline MMSE & -0.017 & 0.902 \\
\hline ZBI & -0.276 & $0.036^{\star}$ \\
\hline BDI & -0.539 & $0.000^{* *}$ \\
\hline BAI & -0.334 & $0.008^{* *}$ \\
\hline BHS & -0.195 & 0.142 \\
\hline People with dementia & & \\
\hline Age & 0.112 & 0.402 \\
\hline Schooling & -0.041 & 0.76 \\
\hline Age of onset & 0.104 & 0.438 \\
\hline Duration of disease & -0.027 & 0.838 \\
\hline ASPIDD & 0.088 & 0.512 \\
\hline PQoL & 0.213 & 0.109 \\
\hline C-PQoL & 0.315 & $0.016 *$ \\
\hline MMSE & -0.078 & 0.559 \\
\hline CSDD & -0.088 & 0.512 \\
\hline FAQ & 0.188 & 0.157 \\
\hline NPI & -0.226 & 0.088 \\
\hline CDR & 0.377 & 0.118 \\
\hline
\end{tabular}

R: correlation coefficient; P: significance; CQoL: quality of life in Alzheimer's Disease scale (caregivers' reports on their own quality of life); MMSE: mini-mental state examination; ZBI: Zarit Burden interview; BDI: beck depression inventory; BAl: beck anxiety inventory; BHS: beck hopelessness scale;ASPIDD: scale of psychosocial impact of the diagnosis of dementia;PQoL: quality of life in Alzheimer's disease scale (patients' reports on their own quality of life); C-PQoL: quality of life in Alzheimer's disease scale (caregivers' reports on patients' quality of life; CSDD: Cornell scale for depression in dementia; FAQ: Pfeffer functional activities questionnaire; NPI: neuropsychiatric inventory; CDR: clinical dementia rating. ${ }^{*} p<0.05 ;{ }^{* \star} p<0.01$. levels of resilience, and a lack of significant relationships, between resilience and the sociodemographic and clinical factors of people with dementia. We can assume that resilience is an individual characteristic. Individuals with lower levels of resilience may be the most concerned and tend to be more susceptible to stress-eliciting situations ${ }^{15}$. Consequently, they may react more strongly to stressful life events and tend to choose dysfunctional coping strategies or attributional patterns ${ }^{15}$. Conversely, individuals who are more resilient may have a positive self-image, self-efficacy and attitude on life ${ }^{8}$. They tend to be realistic, secure, patient and adaptable ${ }^{5}$. Moreover, resilience may allow caregivers to manage and adapt to stressful care demands ${ }^{5}$. It would be helpful for further research to examine the relationship between cultural background and resilience to better characterize whether it is a personal trait or a learned characteristic.

In comparison to caregivers of people with other pathologies, caregivers of people with dementia tend to develop higher levels of depressive symptoms or burden ${ }^{4}$. Our findings are in line with other studies, as we showed that moderate to higher levels of resilience were related to lower levels of depressive symptoms ${ }^{3,27}$. Resilience is a protective factor for depression associated with decreased stress ${ }^{14}$. Previous research has shown that resilience can be understood as the personality trait that underlies the experience of stressful life events and stronger stress reactivity $^{5,15}$. Resilient people have the ability to consider a broader range of experience and to 'hang loose' and take what comes, thus moderating extreme responses to adversity $^{13}$. A sense of self-efficacy ${ }^{13}$ and internal locus of control $^{8}$ facilitate a more resilient behavior when confronting stressful situations, reducing the stress vulnerability and risk of depression, anxiety and burden ${ }^{3,8}$.

Our study showed a significant relationship between resilience and caregivers' QoL. Resilience is considered to act as a protective factor by increasing the QoL, coping and overall adaptation to difficulties related to caregivers ${ }^{11}$. The QoL involves the individuals' subjective perceptions about their role in life, based on their culture and system of values ${ }^{28}$. It is a multidimensional and complex concept that encompasses several dimensions ${ }^{28}$. It seems that resilience helps caregivers maintain their mental and physical

Table 4. Regression model of factors related to caregivers' resilience.

\begin{tabular}{lcccccc} 
Variable & $\mathrm{B}$ & $\boldsymbol{B}$ & $\mathrm{R}^{2}$ & $\mathrm{Adj} . \mathrm{R}^{2}$ & $\mathrm{t}$ & Significance \\
\hline CQoL & $-1290,8$ & -0.389 & 0.378 & 0.343 & -2.750 & $0.008^{*}$ \\
BDI & -0.734 & -0.331 & & & -2.097 & $0.048 *$ \\
BAl & 0.128 & 0.065 & & & 0.452 & 0.653 \\
\hline
\end{tabular}

B: linear coefficient; $\beta$ : standardized beta coefficient; $\mathrm{R}^{2}$ : coefficient of determination; Adj. R2 : adjusted R squared values; CQoL: quality of life in Alzheimer's disease scale (caregivers' reports on their own quality of life); BDI: Beck depression inventory; BAI: Beck anxiety inventory. ${ }^{\star} p<0.05$. 
stability, fostering caregiving and providing better health, and QoL for the care recipient ${ }^{2}$. Despite the negative consequences of caregiving, how the caregiver interprets the situation, the strategies adopted to deal with it, and their features and personality traits, are crucial variables for the development of different levels of resilience ${ }^{2}$. For these reasons, we can consider that the relationship between resilience and different variable groups is bidirectional, including depressive symptoms and QoL.

In contrast to some studies ${ }^{1,2,5}$, our findings showed that resilience was not related to burden. The presence of burden depends on a series of subjective factors ${ }^{29}$. We can suppose that the clinical symptoms of dementia are possibly not perceived as uncontrollable by the caregivers assessed in this study. Gallagher et al. ${ }^{29}$ have shown that high self-efficacy in dementia caregivers could mitigate the symptoms of burden and depression. In addition, caregivers with an internal locus of control, regarding the person with dementia's behavior, would be less susceptible to the negative consequences caused by stress ${ }^{30}$. In fact, beliefs about one's own abilities and internal locus of control are two factors that support the construct of resilience $^{8}$. Hence, optimistic people with a high degree of self-efficacy will probably show more resilient behavior when confronting stressful situations, which may reduce the stress vulnerability and risk of burden.

Another important result of our study is the lack of relationship between resilience and caregivers' sociodemographic variables. The majority of our caregivers were female with moderate levels of schooling. Education is an important factor in Latin American countries because of the high levels of illiteracy. Educational background might play a key role in facilitating caregivers' difficulties, but resilience was not related to years of schooling.

In addition, our findings showed that resilience was not related to caregivers' gender. Overall, female caregivers seem to be more vulnerable. Researchers have shown that women tend to be more burdened by caregiving tasks, report more difficulties, and perceive the experience as less rewarding than their male counterparts ${ }^{15}$. Besides, increased stress and burden in females may be due to their involvement in multiple roles such as wife, daughter, mother, and caregiver $^{4}$. As well as for men, the transition into the caregiving role is marked by the undertaking of household chores and changes in the care of kin. By contrast, this part of the transition may be less salient for female caregivers who are often already in charge of such (household) activities. Thus, different definitions of care may result in sex-role-specific experiences of burden and their related effects on personality development. Although the burden tends to be more associated with the female population, one study showed that constructs like resilience could modulate this association $^{30}$. Hence, the lack of relationship between resilience and caregivers' gender and schooling led us to assume that resilience might be related to individual characteristics rather than sociodemographic characteristics.

\section{LIMITATIONS}

We studied a small convenience sample. Further studies should randomize the participants according to disease severity and dementia etiology. In addition, our study had a cross-sectional design and, since resilience is a subjective construct, it may increase over time. A longitudinal study would have allowed us to observe changes in the caregivers' resilience over time. Despite these limitations, the results of the present study are notable due to the lack of research on the resilience of dementia caregivers in Brazil.

In conclusion, the majority of dementia caregiving research has focused on the negative aspects of care. Overall, our findings offer several clinical contributions to the positive aspects of care. Our data may allow some comparisons across cultural and national boundaries, which may be valuable in assessing how different cultural and psychosocial environments may influence caregivers' resilience. We found that the presence of resilience is related to a decrease in caregivers' depressive symptoms and increase in their QoL. We can assume that resilience is associated with the individual's characteristics and abilities and is not related to the clinical state of the person with dementia. Understanding the factors related to resilience may lead to the development of psychological and educational support for caregivers of people with dementia. Support groups should be focused not only on information and feelings about the diagnosis and caregiving routines, but also on the factors that may increase resilience among caregivers, such as task-focused coping strategies and self-efficacy.

\section{References} dementia. Int J Ment Health Nurs. 2013;22(4):340-6. doi:10.1111/j.1447-0349.2012.00877.x

2. Fernández-Lansac V, Crespo López M, Cáceres R, Rodríguez-Poyo M. [Resilience in caregivers of patients with dementia:a preliminary study]. Rev Esp Geriatr Gerontol. 2012;47(3):102-9. Spanish. doi:10.1016/j.regg.2011.11.004
3. Lavretsky H, Siddarth P, Irwin MR. Improving depression and enhancing resilience in family dementia caregivers: a pilot randomized placebo-controlled trial of escitalopram. Am J Geriatr Psychiatry. 2010;18(2):154-62. doi:10.1097/JGP.0b013e3181 beab1e

4. Fitzpatrick KE, Vacha-Haase T. Marital satisfaction and resilience in caregivers of spouses with dementia. Clin Gerontol. 2010;33(3):165-80. doi:10.1080/07317111003776547 
5. Gaugler J. Kane RL, Newcomer R. Resilience and transitions from dementia caregiving.J Gerontol B Psychol Sci Soc Sci. 2007;62(1):P38-44.

6. Shuter P, Beattie E, Edwards H. An exploratory study of grief and health-related quality of life for caregivers of people with dementia. Am J Alzheimers Dis Other Demen. 2014;29(4):379-85. doi:10.1177/1533317513517034

7. Sousa MF, Santos RL, Turró-Garriga O, Dias R, Dourado MC. Factors associated with caregiver burden: comparative study between Brazilian and Spanish caregivers of patients with Alzheimer's disease (AD). Int Psicogeriatria. 2016:28(8):1363-74.

8. Contador I, Fernández-Calvo B, Palenzuela DL, Miguéis S, Ramos F. Prediction of burden in family caregivers of patients with dementia: a perspective of optimism based on generalized expectancies of control. Aging Ment Health. 2012;16(6):675-82. doi:10.1080/13607863.2012.684666

9. Wilks SE, Little KG, Gough HR, Spurlock WJ. Alzheimer's aggression: influences on caregiver coping and resilience. J Gerontol Soc Work. 2011;54(3):260-75. doi:10.1080/01634372.2010.544531

10. Reppold CT, Mayer JC, Almeida LS, Hutz CS. [Resilience assessment: controversies about the use of scales]. Psicol Reflex Crít. 2012;25(2):248-55. Portuguese. doi:10.1590/S0102-79722012000200006

11. Trapp SK, Perrin PB, Aggarwal R, Peralta SV, Stolfi ME Morelli E et al. Personal strengths and health related quality of life in dementia caregivers from Latin America. Behav Neurol. 2015;2015:507196. doi:10.1155/2015/507196

12. Dias R, Santos RL, Sousa MFB, Nogueira M, Torres B, Belfort T et al. Resilience of caregivers of people with dementia: a systematic review of biological and psychosocial determinants. Trends Psychiatry Psychother. 2015;37(1):12-9. doi:10.1590/2237-6089-2014-0032

13. Wagnild GM, Young HM. Development and psychometric evaluation of the Resilience Scale. J Nurs Meas. 1993;1(2):165-78.

14. Yunes MAM. [Positive psychology and resilience: focus on the individual and families]. Psicol Estud. 2003;8 n esp:75-84. Portuguese. doi:10.1590/S1413-73722003000300010

15. Rohr MK, Wagner J, Lang FR. Effects of personality on the transition into caregiving. Psychol Aging. 2013;28(3):692-700. doi:10.1037/a0034133

16. American Psychiatric Association. Diagnostic and statistical manual of mental disorders: text revision. 4th ed. Washington, DC: American Psychiatric Association; 2002

17. Maia AL, Godinho C, Ferreira ED, Almeida V, Schuh A, Kaye J et al. [Application of the Brazilian version of the CDR scale in samples of dementia patients]. Arq Neuropsiquiatr. 2006;64(2B):485-9. Portuguese. doi:10.1590/S0004-282X2006000300025

18. Bertolucci PH, Brucki SM, Campacci SR, Juliano Y. [The mini-mental state examination in a general population: impact of educational status]. Arq Neuropsiquiatr. 1994;52(1):1-7. Portuguese. doi:10.1590/S0004-282X1994000100001
19. Pesce RP, Assis SG, Avanci JQ, Santos NC, Malaquias JV, Carvalhaes R. [Cross-cultural adaptation, reliability and validity of the resilience scale]. Cad Saude Publica. 2005;21(2):436-48. Portuguese. doi:10.1590/S0102-311X2005000200010

20. Cunha JA. Manual das versões em português das escalas Beck. São Paulo: Casa do Psicólogo; 2001.

21. Novelli MM, Nitrini R, Caramelli P. Validation of the Brazilian version of the quality of life scale for patients with Alzheimer's disease and their caregivers (QOL-AD). Aging Ment Health. 2010;14(5):624-31. doi:10.1080/13607861003588840

22. Scazufca M. Brazilian version of the Burden Interview scale for the assessment of burden of care in carers of people with mental illnesses. Rev Bras Psiquiatr. 2002;24(1):12-17. doi:10.1590/S1516-44462002000100006

23. Dutra MC, Ribeiro RS, Pinheiro SB, Melo GF, Carvalho GA. Accuracy and reliability of the Pfeffer Questionnaire for the Brazilian elderly population. Dement Neuropsychol. 2015;9(2):176-83. doi:10.1590/1980-57642015DN92000012

24. Portugal MG, Coutinho ES, Almeida C, Barca ML, Knapskog $\mathrm{AB}$, Engedal K et al. Validation of Montgomery-Åsberg rating scale and Cornell scale for depression in dementia in Brazilian elderly patients. Int Psychogeriatrics. 2012;24(8):1291-8. doi:10.1017/S1041610211002250

25. Camozzato AL, Kochhann R, Simeoni C, Konrath CA, Pedro Franz A, Carvalho A et al. Reliability of the Brazilian Portuguese version of the Neuropsychiatric Inventory (NPI) for patients with Alzheimer's disease and their caregivers. Int Psychogeriatr. 2008;20(2):383-93. doi:10.1017/S1041610207006254

26. Dourado MCN, Mograbi DC, Santos RL, Sousa MF, Nogueira $\mathrm{ML}$, Belfort T et al. Awareness of disease in dementia: factor structure of the assessment scale of psychosocial impact of the diagnosis of dementia. J Alzheimer's Dis. 2014;41(3):947-56. doi:10.3233/JAD-140183

27. O'Rourke N, Kupferschmidt AL, Claxton A, Smith JZ, Chappell $\mathrm{N}$, Beattie BL. Psychological resilience predicts depressive symptoms among spouses of persons with Alzheimer disease over time. Aging Ment Health. 2010;14(8):984-93. doi:10.1080/13607863.2010.501063

28. Santos RL, Sousa MF, Simões-Neto JP, Nogueira ML, Belfort TT, Torres B et al. Caregivers' quality of life in mild and moderate dementia. Arq Neuropsiquiatr. 2014;72(12):931-7. doi:10.1590/0004-282X20140155

29. Gallagher D, Ni Mhaolain A, Crosby L, Ryan D, Lacey L, Coen RF et al. Self-efficacy for managing dementia may protect against burden and depression in Alzheimer's caregivers. Aging Ment Health. 2011;15(6):663-70. doi:10.1080/13607863.2011.562179

30. Gallicchio L, Siddiqi N, Langenberg P, Baumgarten M. Gender differences in burden and depression among informal caregivers of demented elders in the community. Int J Geriatr Psychiatry. 2002;17(2):154-63. doi:10.1002/gps.538 